Published in final edited form as:

Resuscitation. 2009 September 1; 5(5): 441. doi:10.1016/j.jalz.2009.04.002.

\title{
Response to Letter to the Editor by Doniger
}

\section{Katherine V. Wild, Ph.D.}

To the Editor:

Drs. Doniger and Simon of the Neurotrax Corporation cite inaccuracies related to their test, Mindstreams, in our review paper published in this journal in November 2008. We thank them for their careful reading of the paper and would like to respond to their concerns. Firstly, any such review article is a reflection of the data available at one point in time, which is typically at least several months prior to publication. Further, as stated in our Methods section, we relied on database search strategies to identify publications of interest; unfortunately items such as technical reports by the U.S. Navy are overlooked by such methods. The 2008 paper they cite was indeed referenced in our discussion, but as that paper dealt with ease of use rather than additional normative data, those analyses were not part of our table.

Results that included other diagnostic groups were reported in the context of comparisons to Alzheimer's populations in those studies, as with the CANTAB (Parkinson's disease) and the COGDRAS-D (Huntington's disease), and so were deemed appropriate for inclusion. Similarly, the scores for "Administration/Interface" as described in our appendix rely on interface design as well as degree of assistance required, rather than on the undoubted clinical benefit of having an examiner present. The inaccuracy regarding number of subtests was based on an article describing the Mild Impairment Battery wherein one subtest (Verbal Function) subsumes two tasks, naming and rhyming. We apologize for this confusion. In any case, Mindstreams received the highest rating for comprehensiveness and depth of the battery. While our stated inclusion and rating criteria may be particular to this review, we stand by them as a reasonable approach to this emerging field.

Finally, we hope that readers of our review will use it as a basis for further investigation of any of these or other computerized test batteries, rather than as a final word of recommendation or criticism.

Publisher's Disclaimer: This is a PDF file of an unedited manuscript that has been accepted for publication. As a service to our customers we are providing this early version of the manuscript. The manuscript will undergo copyediting, typesetting, and review of the resulting proof before it is published in its final citable form. Please note that during the production process errors may be discovered which could affect the content, and all legal disclaimers that apply to the journal pertain. 